\title{
Correction to: L-Aspartate, L-Ornithine and L-Ornithine-L-Aspartate (LOLA) and Their Impact on Brain Energy Metabolism
}

\author{
Abhijit Das $^{1,2}$ - Dominik Fröhlich ${ }^{3}$ (1) - Lavanya B. Achanta ${ }^{1,3} \cdot$ Benjamin D. Rowlands $^{1,3} \cdot$ Gary D. Housley $^{3}$ (1) \\ Matthias Klugmann ${ }^{3}$ (D) Caroline D. Rae ${ }^{1,2}$
}

Published online: 7 July 2020

○) Springer Science+Business Media, LLC, part of Springer Nature 2020

\section{Correction to: Neurochemical Research \\ (2020) 45:1438-1450 \\ https://doi.org/10.1007/s11064-020-03044-9}

The original version of this published article, the bottom right hand panels of Figs. 3-6 were labelled as "Isotopomers formed from $\left[1-{ }^{13} \mathrm{C}\right] \mathrm{D}$-glucose". This is incorrect and should read "Isotopomers formed from $\left[1,2-{ }^{13} \mathrm{C}\right]$ acetate". This has been corrected by publishing this correction article.

Publisher's Note Springer Nature remains neutral with regard to jurisdictional claims in published maps and institutional affiliations.

The original article can be found online at https://doi.org/10.1007/ s11064-020-03044-9.

Caroline D. Rae

c.rae@unsw.edu.au

1 Neuroscience Research Australia, Barker St, Randwick, NSW 2031, Australia

2 School of Medical Sciences, The University of New South Wales, Sydney, NSW, Australia

3 Translational Neuroscience Facility, School of Medical Sciences, The University of New South Wales, Kensington 2052, Australia 